\section{PERAN WAWASAN NUSANTRA DALAM SOSIAL DAN BUDAYA}

\section{Danang Fahturosi}

IIK STRADA INDONESIA

ryancooper2033@gmail.com

\begin{abstract}
ABSTRAK
manusia sebagai makhluk Tuhan yang maha esa yang berbudaya sejak zaman dahulu hidup bermasyarakat berkelompokkelompok atas dasar berbagai kesamaan dan kesepakatan kelompok-kelompok masyarakat tersebut membentuk bangsa. bangsa yang telah menegara ( membentuk negara) bangsa tersebut menentukan citacita dan tujuan nasional yang ingin dicapai wawasan nusantara adalah cara pandang terhadap bangsa dengan tujuan menjaga persatuan dan kesatuan yang diwujudkan dengan mengutamakan kepentingan nasional di banding kepentingan pribadi kelompok atau suatu golongan tertentu wawasan nusantara juga biasa dikenal sebagai wawasan nasional atau wawasan kebangsaan tentang cara pandang dalam kehidupan bermasyarakat berbangsa dan bernegara dengan mengutamakan persatuan dan kesatuan wilayah Indonesia

dalam mewujudkan cita-cita dan mencapai tujuan nasional bangsa memadukan pikiran dan tindakan serta kekuatan tekad dan semangat masyarakat yang bahu-membahu berjuang bersama demi tercapainya citacita dan tujuan yang diinginkan, kepentingan nasional diutamakan melebihi kepentingan pribadi kelompok maupun golongan dan kedaerahan keterpaduan upaya yang disertai tekad dan semangat yang tinggi di dasarkan pada kesamaan persepsi dan cara pandang dalam mencapai tujuan nasional
\end{abstract}

Kata kunci: wawasan nusantara, sosial,budaya

\section{LATAR BELAKANG}

wawasan nusantara adalah cara pandang terhadap bangsa dengan tujuan menjaga persatuan dan kesatuan yang diwujudkan dengan mengutamakan kepentingan nasional di banding kepentingan pribadi kelompok atau suatu golongan tertentu wawasan nusantara juga biasa dikenal sebagai wawasan nasional atau wawasan kebangsaan tentang cara pandang dalam kehidupan bermasyarakat berbangsa dan bernegara dengan mengutamakan persatuan dan kesatuan wilayah Indonesia ditinjau dari geografi Indonesia Indonesia merupakan negara kepulauan maka hal tersebut mengakibatkan kondisi masyarakat dengan multi budaya dalam kehidupan berbangsa dan bernegara keanekaragaman memerlukan suatu perangkat agar bangsa yang bersangkutan dapat bersatu guna memelihara keutuhan negaranya di Indonesia saat ini masih terjadi problem yang belum terselesaikan Indonesia sebagai negara kepulauan melahirkan keragaman Ras Suku dan budaya potensi akan terjadinya konflik budaya an tidak dapat dihindari pada dasarnya masyarakat Indonesia masih belum menyadari atau mempelajari konsep dasar kewarganegaraan sehingga rawan terjadinya konflik faktor utama dari konflik tersebut adalah rendahnya kesadaran masyarakat sebagai bagian dari kesatuan bangsa Indonesia sering terjadi nya masalah hanya akan memecah semangat persatuan dan kesatuan bangsa, meningkatkan wawasan nusantaramerupakan tugas seluruh warga negara Indonesia khususnya mahasiswa dan Pemuda sebagai penggerak masyarakat harus selalu menerapkan pengetahuan tentang wawasan nusantara

\section{KASUS/MASALAH}


Berdasarkan latar belakang yang telah dibahas di atas maka dapat ditentukan kasus/ masalah :

1.Apakah pengertian dari Wawasan

Nusantara?

2.Bagaimana cara meningkatkan

Wawasan Nusantara?

3.apa fungsi dan tujuan wawasan nusantara ?

\section{TINJAUAN PUSTAKA}

Sejak proklamasi kemerdekaan 17 Agustus 1945 kebangsaan Indonesia tidak didasarkan pada kesamaan suku etnis agama budaya atau adat istiadat tetapi didasarkan pada kesamaan cita-cita yang ditegaskan dalam pembukaan undangundang Dasar 1945 yaitu Negara Indonesia merdeka, berdaulat adil dan makmur dalam pasal 1 ayat 1 undang-undang Dasar 1945 Negara Indonesia ialah negara kesatuan yang berbentuk republik perpecahan dalam kehidupan berbangsa sampai saat ini bersumber pada perbedaan cita negara

Kebudayaan nasionalitu merupakan "puncak-puncak dari kebudayaan daerah" sebagaimana apa yang dikatakan ole Ki Hahar Dewantara.Politik Kebudayaan Nasioanl tidak hanya menyatakan drinya dalam Kongre sKebudayaan tahun 1991, namun Kebudayaan Nasional secara tidak langsung "disebarluaskan"dan diwujudkan melalui penataran ideologi, yaitu penataran Pedoman Penghayatan dan Pengamalan Pancasila(P-4). Pancasila menjadi sumber dari semua nilai danaturan (norma) dan ditempatkan pada kedudukan tolak ukur tunggal bagi nilai dan norma yang berlaku dan boleh dipedomi, sebagai arah dalam kehidupan berbangsa dan bernegara (Bangun,1991). MPR-RI melalui amandemen kedua UUD 1945, telah mengamanatkan dalam Pasal 18B ayat(2) bahwa: "Negara mengakui dan menghormati kesatuan-kesatuan masyarakat hukum adat beserta hak-hak tradisionalnya sepanjang masih hidup dan sesuai dengan perkembangan masyarakat dan prinsip Negara Kesatuan Republik Indonesia, yang diatur dalam undangundang". Berdasarkan peraturan tersebut dapat kita ketahui bahwa undang-undang mengakui perbedaan suku bangsa yang besar diantara penduduk Indonesia dan menjamin persamaan status bagi semua suku bangsa yang ada tanpa melihat besarnya penduduk masing-masing suku bangsa.Semua suku bangsa memiliki hak yang sama untuk mengembangkann kebudayaan dan Bahasa mereka masingmasing,membentuk pusat-pusat kebudayaan mereka sendiri,museum, dan lain-lain, namun bahasayang digunakan dalam pendidikan resmi adalah bahasa Indonesia

\section{PEMBAHASAN}

\section{Pengertian wawasan nusantara}

adalah cara pandang terhadap bangsa dengan tujuan menjaga persatuan dan kesatuan yang diwujudkan dengan mengutamakan kepentingan nasional dibanding kepentingan pribadi, kelompok, atau suatu golongan tertentu.

Wawasan nusantara juga biasanya dikenal sebagai wawasan nasional dan wawasan kebangsaan tentang cara pandang dalam kehidupan bermasyarakat, berbangsa, dan bernegara dengan mengutamakan persatuan dan kesatuan wilayah Indonesia.

Tak hanya itu, menurut sudut pandang geopolitik Indonesia secara mendasar, wawasan nusantara secara harfiah merupakan konsep kepulauan; secara kontekstual istilah ini lebih tepat diterjemahkan sebagai "visi kepulauan Indonesia".

Dalam hal ini, wawasan nusantara adalah cara bangsa Indonesia memandang dirinya sendiri secara geografis, sebagai suku kesatuan antara ideologi, politik, ekonomi, sosiokultural, serta masalah keamanan dan pertahanan.

\section{Secara Etimologi}


Secara etimologi, pengertian wawasan nusantara berasal dari bahasa Jawa yakni "wawas". Wawas memiliki arti pandangan. Selanjutnya nusa memiliki arti kesatuan kepulauan dan antara yang bermakna dua samudera.

Secara umum, pengertian dari wawasan nusantara adalah cara pandang atau cara melihat kesatuan kepulauan yang terletak di antara Asia dan Australia, juga di antara dua samudera, Hindia dan Pasifik.

\section{Menurut Tap MPR tahun 1993 dan 1998}

Berdasarkan Ketetapan MPR (Tap MPR) tahun 1993 dan 1998 tentang GBHN, pengertian wawasan nusantara merupakan cara pandang dan sikap bangsa Indonesia. Wawasan nusantara juga tentang jati diri dan lingkungan yang mengutamakan persatuan dan kesatuan bangsa, serta kesatuan wilayah demi tercapainya tujuan nasional.

\section{Menurut Tap MPR tahun 1999}

Sementara itu, bunyi Tap MPR tahun 1999 tentang wawasan nusantara adalah, "Wawasan nusantara adalah cara pandang dan sikap bangsa mengenai diri dan lingkungan yang serba beragam dan nilai strategis dengan mengutamakan persatuan dan kesatuan bangsa serta wilayah dalam menyelenggarakan kehidupan bermasyarakat, berbangsa, dan bernegara dengan tujuan mencapai tujuan nasional".

Pengertian Wawasan Nusantara Menurut

Ahli

Tak hanya secara umum dan sesuai dengan Ketetapan MPR, wawasan nusantara juga memiliki pengertian tersendiri menurut beberapa ahli. Berikut ini pengertian wawasan nusantara menurut para ahli.

\section{Prof. Wan Usman}

Wawasan nusantara menurut Prof. Wan Usman adalah cara pandang bangsa Indonesia mengenai diri dan tanah air sebagai negara kepulauan dalam segala aspek kehidupan yang beragam.

\section{Munadjat Danusaputro (1981)}

Sementara itu, Munadjat Danusaputro berpendapat bahwa wawasan nusantara adalah cara pandang bangsa Indonesia tentang diri dan lingkungannya dalam eksistensi yang saling berhubungan serta penerapannya di tengah lingkungan berdasarkan asas nusantara.

Asas nusantara dalam wawasan nusantara ini menurut Munadjat Danusaputro adalah suatu ketentuan dasar yang harus ditaati, dipatuhi, dan dipelihara agar kepentingan nasional dapat terwujud.

\section{Cara meningkatkan wawasan nusantara}

Dalam substansi persatuan dan kesatuan bangsa mengandung makna bahwa kita senantiasa harus bersatu. Sejarah mengajarkan betapa pentingnya persatuan dan kesatuan itu. Cara Meningkatkan rasa Persatuan dan Kesatuan Melalui Wawasan Nusantara antara lain

:1.Meningkatkan semangat kekeluargaan, gotong-royong, dan musyawarah.

2.Meningkatkan kualitas hidup bangsa Indonesia dalam berbagai aspek kehidupan.

3.Meratakan pembangunan serta berkeadilan sosial bagi seluruh rakyat Indonesia.

4.Melaksanakan otonomi daerah guna meningkatkan kesejahteraan masyarakat di daerah.

5.Memperkuat sendi-sendi hukum nasional serta adanya kepastian hukum.

6.Melindungi, menjamin, serta menjunjung tinggi hak asasi manusia. 
7.Memperkuat sistem pertahanan dan keamanan sehingga masyarakat merasa terlindungi

\section{Fungsi dan Tujuan wawasan nusantara}

Fungsi Wawasan Nusantara berfungsi sebagai pedoman, motivasi, dorongan, serta rambu-rambu dalam menentukan segala kebijaksanaan, keputusan, tindakan, dan perbuatan bagi penyelenggara negara di tingkat pusat dan daerah maupun bagi seluruh rakyat Indonesia dalam kehidupan bermasyarakat, berbangsa dan bernegara.TujuanWawasan Nusanatara bertujuan untuk mewujudkan nasionalisme yang tinggi di segala aspek kehidupan rakyat Indonesia yang lebih mengutamakan kepentingan nasional daripada kepentingan individu, kelompok, golongan, suku bangsa atau daerah.

\section{KESIMPULAN}

Memplementasi wawasan nusantara dalam kehidupans osial budaya, akan menciptakan sikap yang mengakui, menerima dan juga menghormati segala bentuk perbedaan atau ke Bhinekaan sebagai kenyataan hidup sekaligus karunia Sang Pencipta agar tercipta juga suasana yang aman dan nyaman di negara Indonesia ini. Jad isangat penting mengimplementasikan wawasan nusantara dalam kehidupan Rendahnya pemahaman dasar sebagai warga negara Indonesia menyebabkan etnosentrisme yang dapat mengancam integrase bangsa. Oleh karena itu perlu untuk kita kembali mempelajari Wawasan Nusantara. Perlu adanya pendidikan moral, pengembangan wawasan,ketrampilanserta penanaman rasanasionalisme pada generasi muda, karena merekalah tulang punggung negara dimasa yang akan datang. Salah satunya melalui penanaman nilai-nilai kepribadian bangsa Indonesia yang tercermin dalamPancasila dan semboyan bangsakita

"BhinekaTunggalEka" kepada mereka sehingga mereka kelak ketika mereka menjadi pemimpin

\section{DAFTAR PUSTAKA}

Adibowo, R. (2010). Wawasan Nusantara Indonesia.

Triwahyuni, D. (2010). Wawasan

Nusantara.

Kusrahmadi, S. D. (2017).

Pentingnya Wawasan Nusantara

dan Integrasi Nasional.

Sodik, M. A., \& Setyani, A. T. (2018). Effect of Smoking For Teens Against Behavior and Social Interaction.

Siyoto, S., \& Sodik, M. A. (2015). Dasar metodologi penelitian. Literasi Media Publishing. 